\title{
IMPLEMENTATION OF '5S' TECHNIQUES IN A TERTIARY CARE TEACHING HOSPITAL
}

\author{
Radha Thapa1, Rishith Prakash², Sunita Saldanha ${ }^{3}$, Muhammed Sabith P4, Kritharth P.K5, Sabeel P.K ${ }^{6}$
}

1Postgraduate Student, Department of Hospital Administration, Yenepoya Medical College, Mangalore, Karnataka, India. ${ }^{2}$ Assistant Hospital Operating Officer, Department of Hospital Administration, Yenepoya Medical College, Mangalore, Karnataka, India. ${ }^{3}$ Associate Professor and Operation Officer (HA), Department of Hospital Administration, Yenepoya Medical College, Mangalore, Karnataka, India.

${ }^{4}$ Assistant Hospital Operating Officer, Department of Hospital Administration, Yenepoya Medical College, Mangalore, Karnataka, India. ${ }^{5}$ Postgraduate Student, Department of Hospital Administration, Yenepoya Medical College, Mangalore, Karnataka, India. ${ }^{6}$ Postgraduate Student, Department of Hospital Administration, Yenepoya Medical College, Mangalore, Karnataka, India.

\section{BACKGROUND}

\section{ABSTRACT}

5S is considered as a foundation for lean, because of its ability to eliminate wastes from non-value added activities or waste from human motion. It is a structured program to systematically organise workplace and boost the morale of workers, promoting a sense of pride in their work.

The objectives of the study are to reduce the process wastes, smoothen the process flow, improve the storage facilities, safety and security through $5 \mathrm{~S}$ techniques at a selective biomedical engineering department; to measure the improvement in $5 \mathrm{~S}$ audit scoring before and after $5 \mathrm{~S}$ implementation.

\section{MATERIALS AND METHODS}

An experimental study was carried out in Yenepoya Medical College Hospital, Mangalore. The effectiveness of 5S techniques were assessed by using $5 \mathrm{~S}$ audit checklist with rating score of each component (audit score ranging from 0 to 5). Photographs before and after the implementation of $5 \mathrm{~S}$ techniques in this study were captured.

\section{RESULTS}

Improvement was observed at the biomedical engineering department that was reflected from the fact that the audit score had increased from $31.79 \%$ to $91.794 \%$. Paired t-test was 8.5673 at $\mathrm{p}<0.0010$.

\section{CONCLUSION}

$5 S$ technique is an inevitable tool to enhance the productivity, safety, acceptable working environment, optimal inventory management and resultant financial benefits of saving inventory cost, smooth workflow, uninterrupted access to materials and tools as and when required. This technique has stood the test of time for improving quality in various organisations such as healthcare, industrial area, business sectors and educational institutions and so forth.

\section{KEY WORDS}

5S, Lean, Maintenance Department, Healthcare Industry, Hospital.

HOW TO CITE THIS ARTICLE: Thapa R, Prakash R, Saldanha S, et al. Implementation of '5S' techniques in a tertiary care teaching hospital. J. Evolution Med. Dent. Sci. 2018;7(35):3840-3846, DOI: 10.14260/jemds/2018/861

\section{BACKGROUND}

Healthcare organisations are increasingly employing Lean tools in an effort to reduce waste while providing high quality healthcare and $5 \mathrm{~S}$ is one of the more popular tools in use to achieve Lean healthcare. ${ }^{1}$ The $5 \mathrm{~S}$ approach is a principle and a tool, which is used to organise and manage the workplace for improvement of the working environment. It originated from the Japanese manufacturing sector in the mid-1950s. The approach became famous and it started to be applied by many companies in the 1980s. It has also been applied in the service industry for example in hotels and hospitals since the 1990s. ${ }^{2}$

'Financial or Other Competing Interest': None.

Submission 07-07-2018, Peer Review 11-08-2018,

Acceptance 17-08-2018, Published 27-08-2018.

Corresponding Author:

Radha Thapa,

Yenepoya Medical College,

Department of Hospital Administration,

Mangalore,

Karnataka, India

E-mail: kusumradhathapa@gmail.com

DOI: $10.14260 /$ jemds $/ 2018 / 861$

\section{S Represents following set of Practices-}

1. Sort: To sort and systematically discard items those are not needed in the workplace.

2. Set in Order: To arrange necessary items in a neat and systematic manner, so that they can be easily retrieved for use and to return after use.

3. Shine: To clean and inspect the workplace thoroughly so that there is no dirt on the floor, machines and equipment etc.

4. Standardise: To maintain a high standard of workplace organisation by keeping everything clean and orderly at all times.

5. Sustain: To train people to practice the $5 \mathrm{~S}$ system continuously, so that it becomes habitual and ingrained in the culture of the organisation. ${ }^{3}$

$5 \mathrm{~S}$ is considered to be the building block or the foundation upon which lean healthcare rests. It is also defined as the process that provides the foundation for building a lean healthcare environment. ${ }^{4} 5 \mathrm{~S}$ activity is not a one-time process, but it is a long-term activity and strategic option for policy makers that needs to be performed as long as an organisation survives. Therefore, $5 \mathrm{~S}$ technique is the 
foundation stone for any organisation as it leads to its continuous improvement in productivity, zero defects, cost reduction, safety in working area and optimal utilisation of resources.

\section{Objectives of the Study}

- To reduce the process wastes, smoothen the process flow, improve storage facilities, safety and security through $5 \mathrm{~S}$ techniques at a selective biomedical engineering department.

- To measure the improvement in $5 \mathrm{~S}$ audit scoring before and after $5 \mathrm{~S}$ implementation.

\section{MATERIALS AND METHODS}

A pre-post study design carried out in Yenepoya Medical College Hospital, Mangalore. Yenepoya Hospital is wellequipped tertiary care teaching hospital with state-of-the-art modern biomedical equipment and with specialty and super specialty services. " $5 S$ " techniques were implemented in biomedical engineering department after understanding the problem faced by biomedical engineers and other healthcare team members. This technique was implemented after discussion and meetings with Hospital Operation Officers, Assistant Hospital Officers and Biomedical Engineers. The effectiveness of $5 \mathrm{~S}$ techniques were assessed by $5 \mathrm{~S}$ audit checklist with rating score of each component. Audit score ranging from 0 to 5 are as follows: no effort- 0 score, slight effort- 1 , moderate effort- 2 , average results- 3 score, above average results- 4 score and outstanding results- 5 score. In audit checklist, SORT component comprised of 6 questions and other components like SET IN ORDER, SHINE, STANDARDISE and SUSTAIN comprised of 11, 10, 7 and 5 questions respectively.

SORT component checklist included questions related to equipment which are either broken, obsolete or unnecessary, required tools present in the area, only required furniture, spare parts, paperwork are present or not- if they are not required then they are red tagged for removal, and tripping hazards like electrical wires and equipment cables are removed from working area.

SET IN ORDER component checklist included whether equipment/ machinery is clearly identified and placed properly, tools have designated storage area within the reach of user; furniture like tables, shelves, cupboard etc. are clearly identified; locations of containers, tool boxes, bins, paperwork, personal protective equipment are clearly defined via signs or marked and properly labelled, fire hoses, fire extinguishers and emergency exit are prominently displayed or not, working conditions are ergonomically friendly or not.

SHINE component checklist consisted of questions related to whether working tools, work surfaces, walls, floors, containers, boxes, bins and personal protective equipment are kept clean or not. Cleaning equipment are stored neatly and readily available or not. Cleaning schedule is present and followed regularly or not.

STANDARDISE component checklist included questions like whether tools, equipment, paperwork, furniture etc. is stored neatly in designated areas and is returned to their proper homes immediately after use or not, equipment maintenance records are visible or not, product waste is consistently and regularly cleaned up or not. The results of the previous audit is posted and clearly visible for entire team or not, whether areas for improvement identified during the previous audit have been addressed and completed, whether work environment which includes lighting, temperature and airflow are satisfying, whether preventive measures have been implemented to ensure the workplace meets $5 \mathrm{~S}$ guidelines.

SUSTAIN component of checklist included questionnaires like whether a member of management has participated in the $5 \mathrm{~S}$ activity, whether recognition is given to the teams involved in the $5 \mathrm{~S}$ activities, whether the team took initiative, time and resources are allocated towards $5 \mathrm{~S}$ activities.

\section{Statistical Analysis}

Data was analysed using the MINITAB version 18 . It was described by using mean, standard deviation and paired $t$ test. $\mathrm{P}<0.001$ was considered to be highly significant.

\section{RESULTS}

After recognising the importance of $5 \mathrm{~S}$ in healthcare, the team members of this study had done thorough discussion and decided to implement the $5 \mathrm{~S}$ management techniques [Figure 1] in Biomedical Engineering Department of Yenepoya Medical College Hospital.

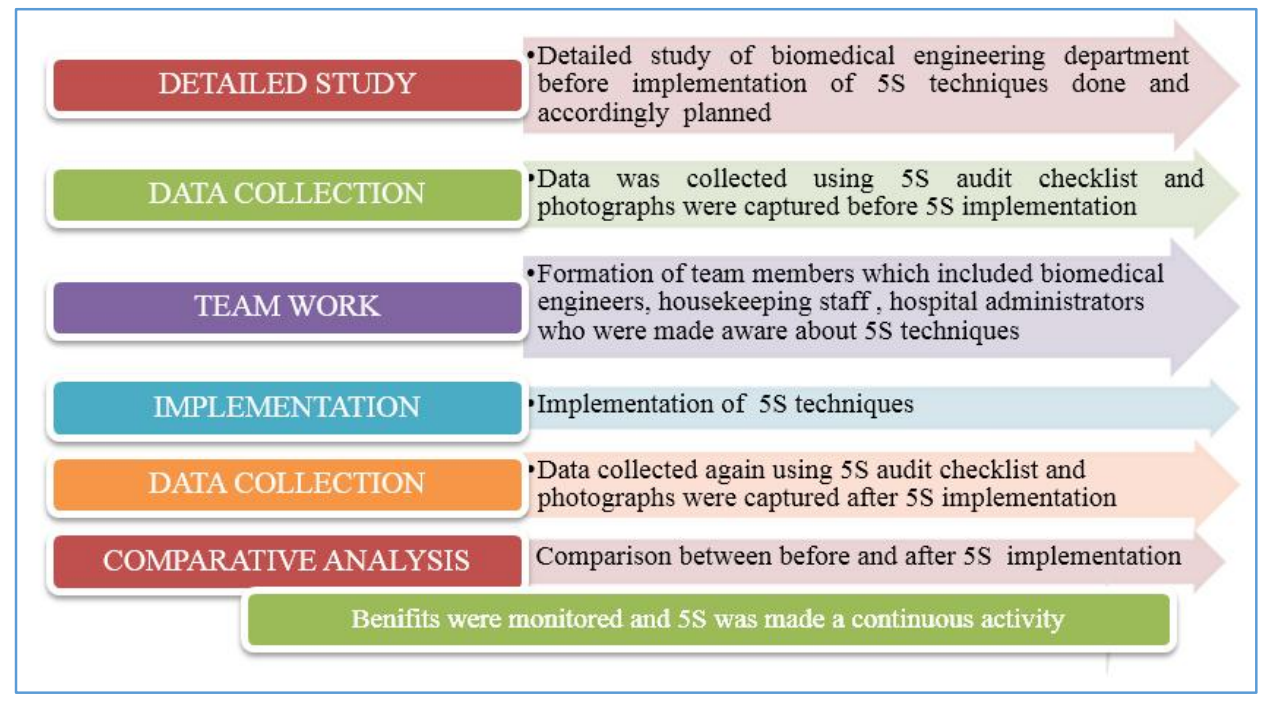

Figure 1. Methodology adopted for implementation of $5 S$ 


\section{S RED TAG}

DATE:

TAGGED BY:

ITEM NAME:

LOCATION:

\begin{tabular}{cl}
\hline CATEGORY \\
$\square \quad$ Equipment \\
$\square \quad$ Tools and Jigs \\
$\square \quad$ Instruments \\
$\square \quad$ Machine parts \\
$\square \quad$ Stationary \\
$\square \quad$ Miscellaneous
\end{tabular}

REASON FOR RED TAG

Not required

Aged/ Obsolete

Defect

Scrap

Other

\section{ACTION TO TAKE}

Return to

Discard

Move to red tag storage area

Move to storage site

\section{COMMENTS}

Figure 2. Red Tag

\section{Sort}

Before the implementation, the areas in Biomedical engineering departments were neither sorted nor specified and equipment were kept in untidy and haphazard manner without labelling. For relevance, Red tag [Figure 2] technique was used for the identification and scrutiny of needed and unwanted items that consumed unnecessary space. The unwanted or equipment which have failed permanently and cannot be put into use were condemned. The main strategy was to reorganise the unwanted items from the items which are required on a daily basis according to their importance, relevance and the frequency of their use to create more space with all the required items available in proximity whenever necessary [Figure 3].

Major Benefits Observed after this Process were-

- Optimal usage of workplace.

- Staff satisfaction.

- Required items available in proximity.

- Increased workspace area and thereby increased productivity. 


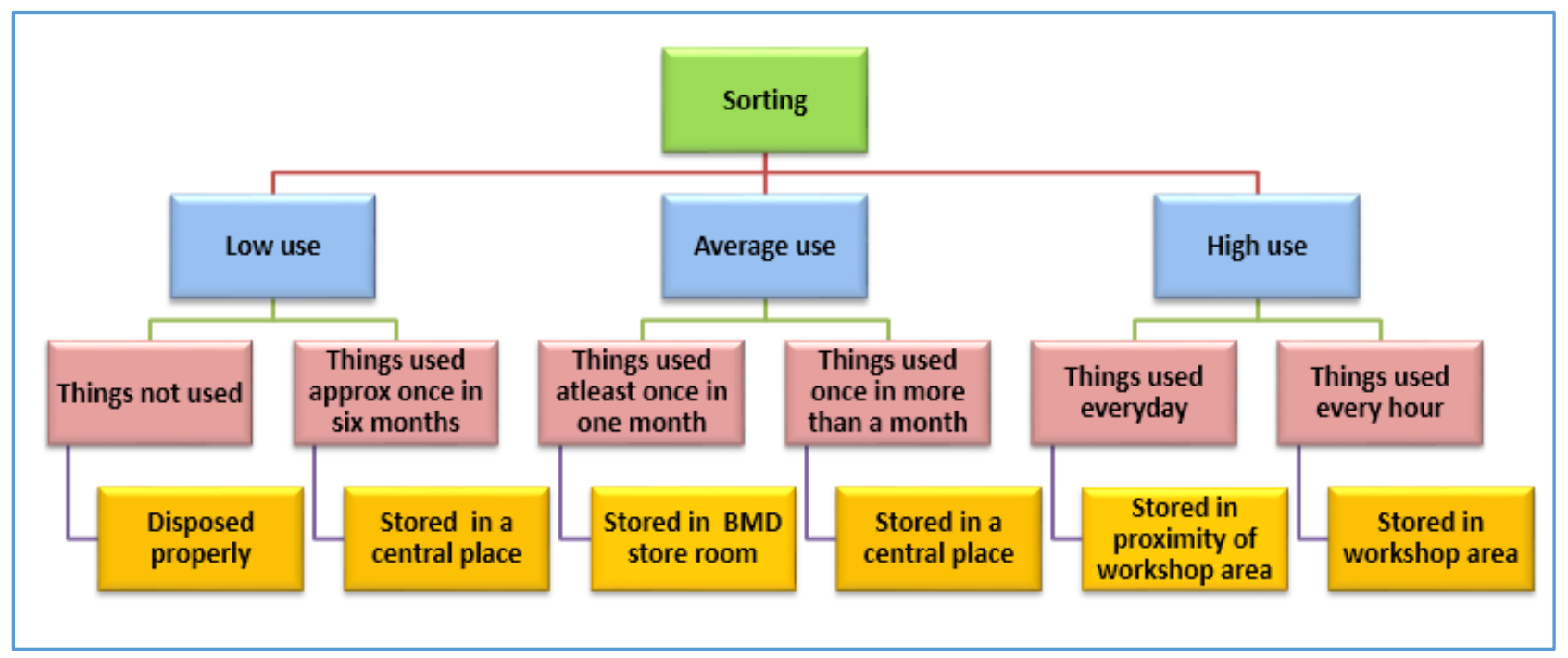

Figure 3. Flowchart of Sorting Process

\section{Set in Order}

The next step taken was the arrangement of equipment and spare parts and vital documents in an organised order. The frequently used tools and spare parts are kept within proximity, easily accessible and at convenient point so that engineers need not travel and lose their valuable time for searching the required items whenever necessary. Items were segregated based on frequency of usage and kept on shelves as per requirement in a visually appealing manner and labelled accordingly. The spare parts are arranged based on FSN technique, i.e. fast moving, slow moving and non-moving. The nomenclature of workshop area, Biomedical Engineer office and storage area were done, and specific areas were allocated for each according to convenience.

\section{Benefits observed after this step were:}

- Reduces the time taken to locate the spare parts.

- The stocks of the spare parts and other necessary items were known precisely.

- Potential health hazards from used equipment were reduced.

- Productivity in work increased.

- $\quad$ Spare parts were readily available.

\section{Shine}

In this stage, all the areas in the Biomedical Engineering Department were washed and cleaned with appropriate solution. The storing shelves, windows and doors were cleaned. The false ceiling that had broken was repaired. A timetable was formulated for housekeeping staff for cleaning on a regular basis to upkeep the department. The hazardous items such as broken glass, syringes, needles and spilled mercury were successfully discarded.

\section{Benefits Observed after this Step were-}

- Visually more appealing.

- Decreased the health hazards caused by broken glasses, spilled mercury and so forth.

\section{Standardise}

An audit checklist was formulated, and certain rules and regulations were formulated and followed accordingly. A drastic improvement was found in workflow.

\section{Sustain}

In this stage, audit was carried out using $5 \mathrm{~S}$ audit checklist and improvement was observed at the Bio-Medical Engineering Department, which was reflected from the fact that the audit score [Table 1 and Table 2] had increased from $31.79 \%$ to $91.794 \%$. In order to sustain for a longer period of time, scoreboard and 5S principles were illustrated to Biomedical Engineers and housekeeping staff, which was also depicted visually in the form of poster on the walls of the department as a reminder to adhere to the $5 \mathrm{~S}$ principles strictly and diligently.

The non-occupied area before the $5 \mathrm{~S}$ implementation in store room increased from 14 square feet to 62 square feet after $5 \mathrm{~S}$ implementation, which indicates an increase in the non-occupied area by 48 square feet after $5 \mathrm{~S}$ implementation.

\begin{tabular}{|c|c|c|c|c|c|c|c|}
\hline 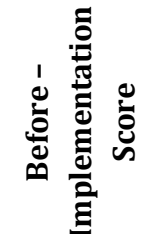 & $\dot{a}$ & 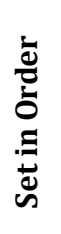 & $\stackrel{\mathscr{Z}}{\mathfrak{B}}$ & 苞 & 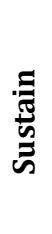 & $\begin{array}{l}\text { तే̃ } \\
\stackrel{0}{0}\end{array}$ & 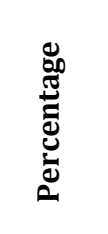 \\
\hline Total score & 30 & 55 & 50 & 35 & 25 & 195 & \multirow{3}{*}{$31.79 \%$} \\
\hline $\begin{array}{c}\text { No. of } \\
\text { questions }\end{array}$ & 6 & 11 & 10 & 7 & 5 & 39 & \\
\hline $\begin{array}{c}\text { Scores } \\
\text { obtained }\end{array}$ & 10 & 18 & 15 & 17 & 2 & 62 & \\
\hline
\end{tabular}




\begin{tabular}{|c|c|c|c|c|c|c|c|}
\hline 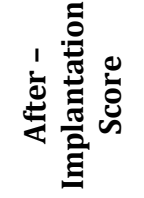 & 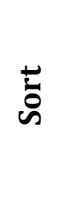 & 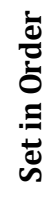 & $\stackrel{\mathscr{E}}{\mathscr{B}}$ & 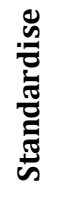 & 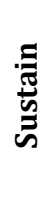 & 풍 & 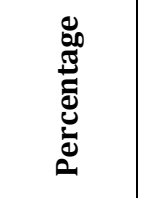 \\
\hline $\begin{array}{l}\text { Total } \\
\text { Score }\end{array}$ & 30 & 55 & 50 & 35 & 25 & 195 & \multirow{3}{*}{$91.794 \%$} \\
\hline $\begin{array}{c}\text { No. of } \\
\text { questions }\end{array}$ & 6 & 11 & 10 & 7 & 5 & 39 & \\
\hline $\begin{array}{c}\text { Scores } \\
\text { obtained }\end{array}$ & 29 & 50 & 42 & 34 & 24 & 179 & \\
\hline
\end{tabular}

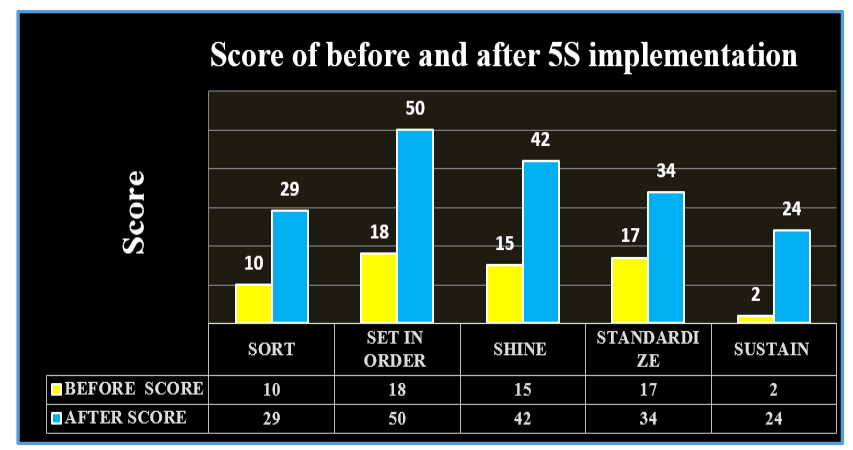

Figure 4. Scores before and after $5 S$ Implementation

Paired t-test [Table 3] was used to look for significant difference between before and after implementation of $5 \mathrm{~S}$ techniques. It was observed that there is a statistically significant difference between before and after implantation

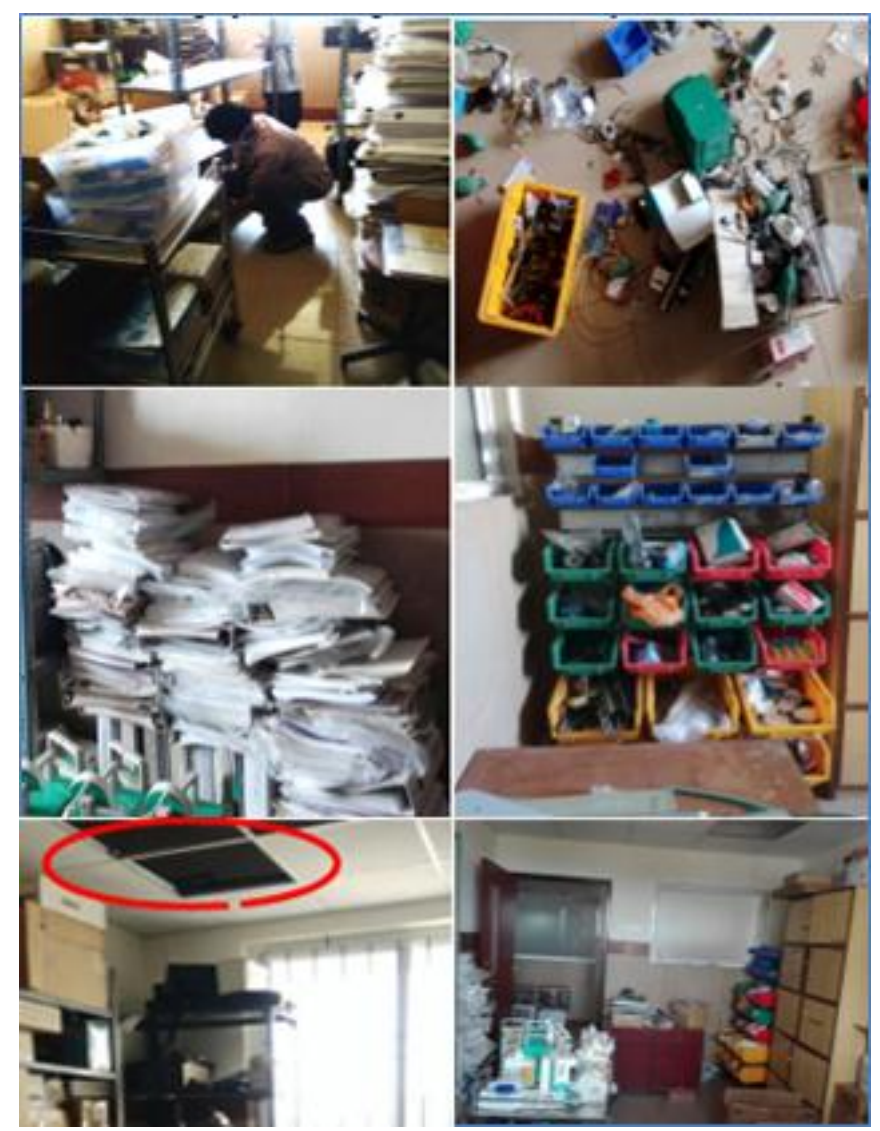

Photographs of Storage Area before $5 S$ Implementation of $5 \mathrm{~S}$ technique. The two-tailed p-value equals 0.0010 and by conventional criteria this difference is considered very statistically significant. The mean difference between before $5 \mathrm{~S}$ and after $5 \mathrm{~S}$ equals to -23.40 [Figure 5]. 95\% confidence interval of this difference from -30.98 to -15.82 , which indicates that $5 \mathrm{~S}$ technique is an indispensable tool to improve quality in healthcare setup.

\begin{tabular}{|c|c|c|c|c|c|c|c|}
\hline & Mean & SD & $\begin{array}{c}\text { SE } \\
\text { Mean }\end{array}$ & $\begin{array}{c}\text { T- } \\
\text { value }\end{array}$ & df & $\begin{array}{c}\text { Standard } \\
\text { Error of } \\
\text { Difference }\end{array}$ & $\begin{array}{c}\text { P- } \\
\text { value }\end{array}$ \\
\hline $\begin{array}{c}\text { Before } \\
\text { 5S }\end{array}$ & 12.40 & 6.58 & 2.94 & 8.5673 & 4 & 2.731 & 0.0010 \\
\hline $\begin{array}{c}\text { After } \\
5 S\end{array}$ & 35.80 & 10.35 & 4.63 & & & & \\
\hline \multicolumn{7}{|c|}{ Table 3. Paired T-Test Result } \\
\hline
\end{tabular}

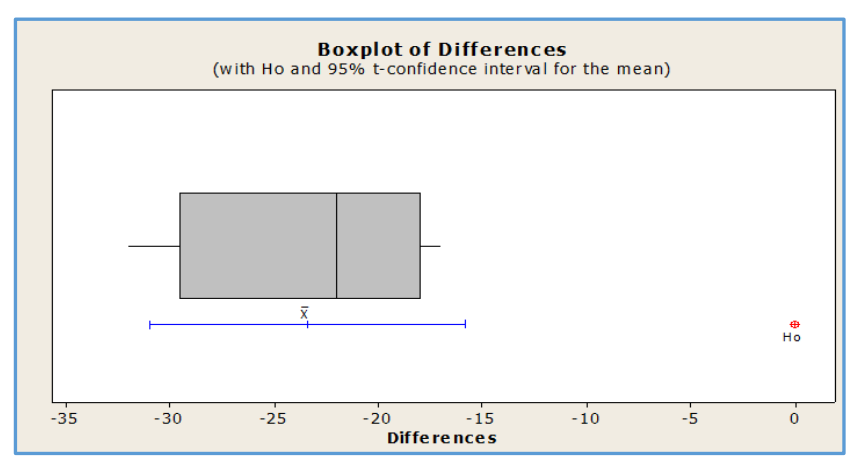

Figure 5. Box Plot Differences
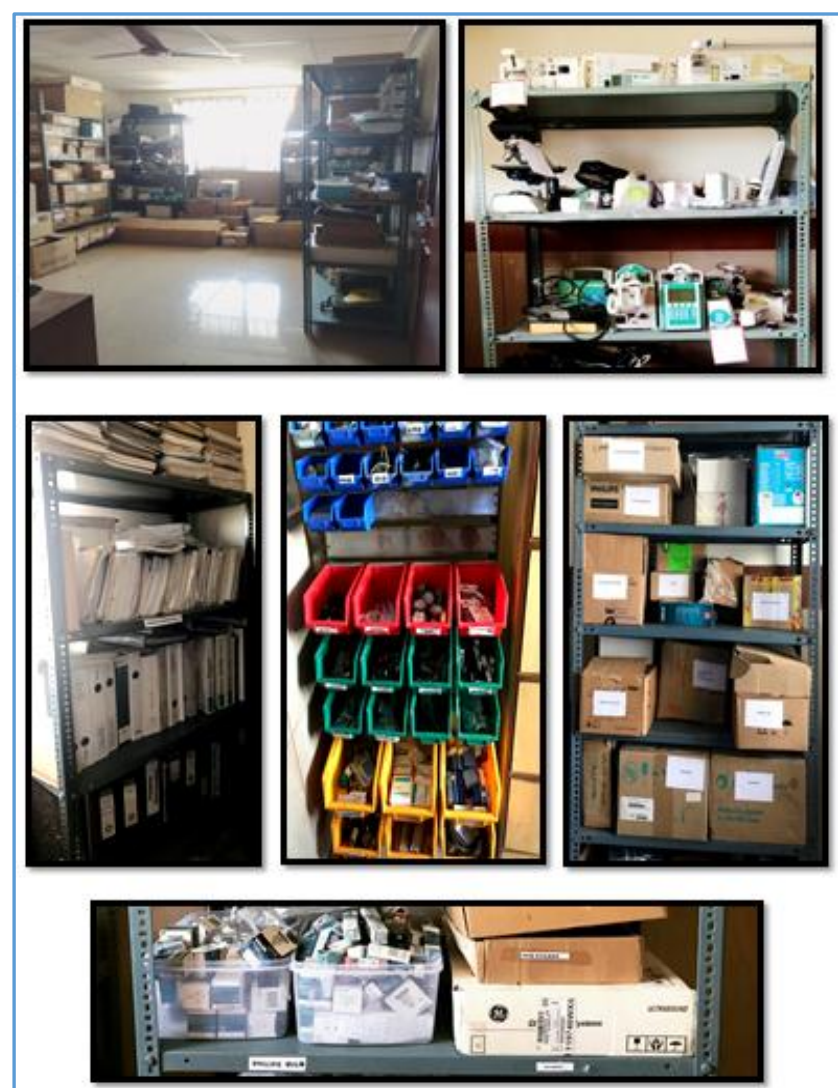

Photographs of Storage Area after $5 S$ Implementation 


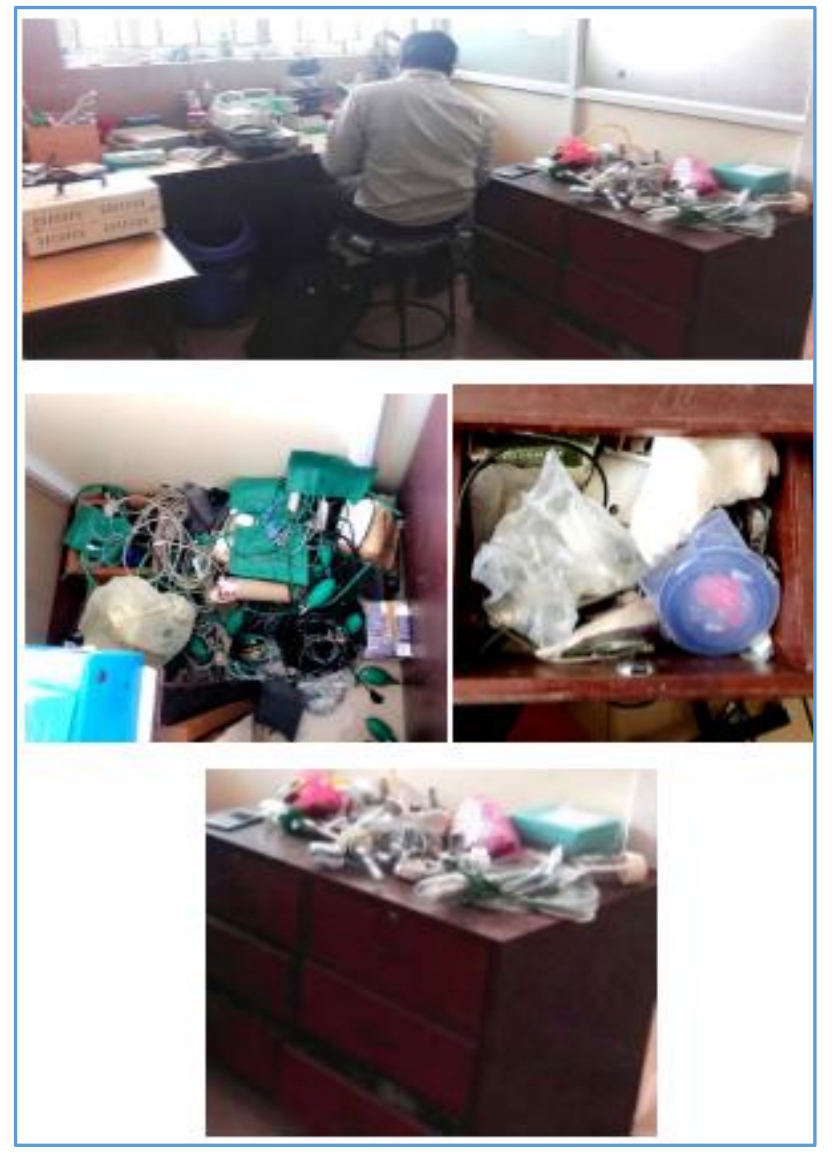

Photographs of Workshop Area before $5 S$ Implementation

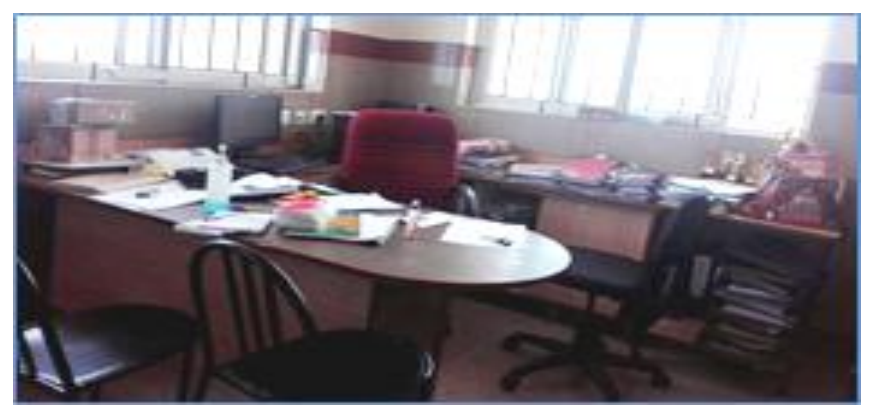

Photograph of BME Office Area before $5 S$ Implementation

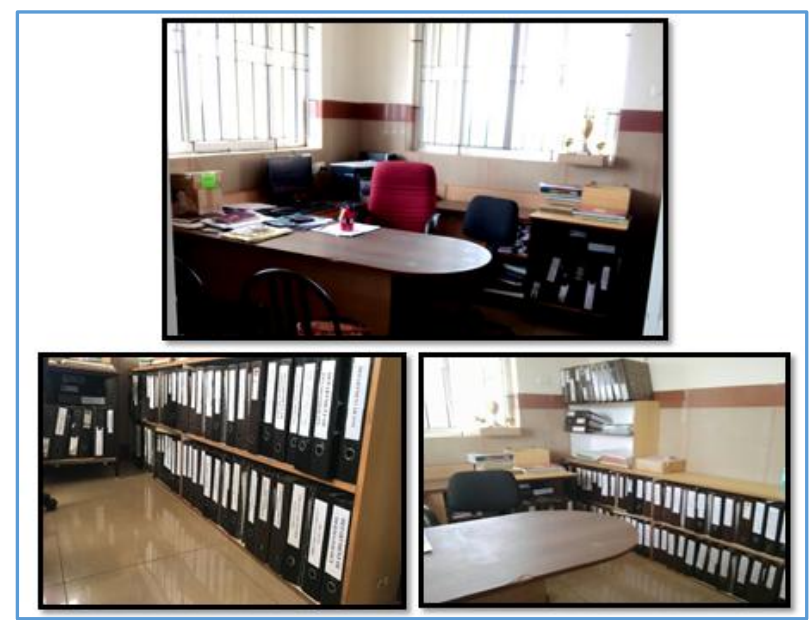

Photograph showing BME Office Area after $5 S$ Implementation

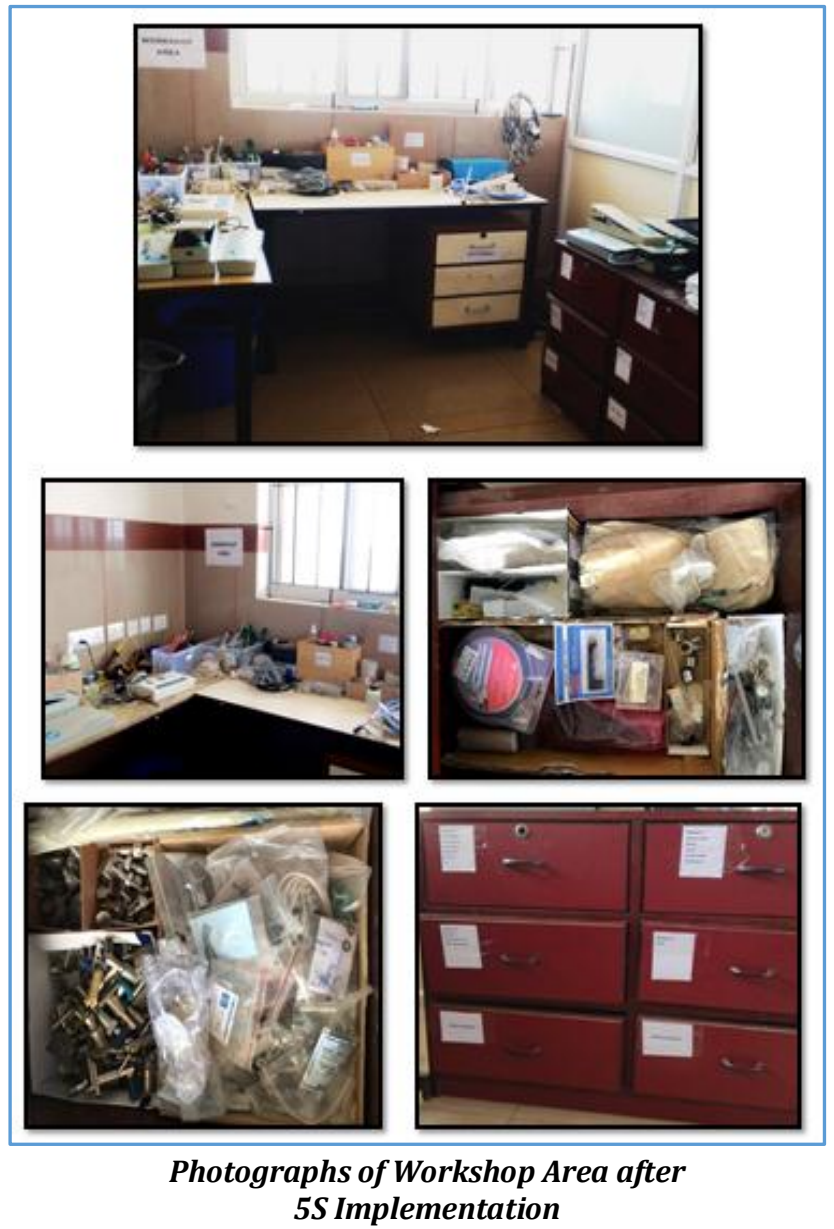

\section{DISCUSSION}

In a study done by Shogo Kanamori et $\mathrm{al}^{5}$ at a health centre in Senegal 'Implementation of 5S management method for lean healthcare at a health centre in Senegal: a qualitative study of staff perception' adopted $5 \mathrm{~S}$ technique to improve the working condition at a healthcare centre. In this study, $5 \mathrm{~S}$ technique was implemented in Biomedical Engineering Department of a tertiary care teaching hospital and found similar results like the above-mentioned study. After application of $5 \mathrm{~S}$ technique, following benefits were found which includes-

- Improved hygiene and cleanliness.

- Fewer unwanted items.

- Improved orderliness of items.

- Improved labelling and directional.

- Indicators of service units.

- Reduction in time searching for items.

- Increased reuse of items.

- Improved collaboration among staff members.

- Increased awareness of 5S.

In our study $5 \mathrm{~S}$ auditing was conducted using a checklist and scoring was done which varied from $0-5$, and the total scoring for each $5 \mathrm{~S}$ component sorting, set in order, shine, standardise and sustain was found to be $10 \%, 32.7 \%, 30 \%$, $48.57 \%$ and $8 \%$ respectively before $5 \mathrm{~S}$ implementation which had increased exponentially to $96.66 \%, 90.90 \%, 84 \%, 97.14 \%$ and $96 \%$ after $5 \mathrm{~S}$ implementation respectively. The average scoring before $5 \mathrm{~S}$ implementation varied from $0-3$, which improved to an average score of 4 to 5 after $5 \mathrm{~S}$ implementation which indicates a dramatic improvement in the efficiency, productivity, safety, optimal utilisation of resources, increased 
work space, clean work environment and financial benefits indirectly by enhancing inventory management. A similar study was conducted by AR Abdul et $\mathrm{al}^{6}$ and observed that before the implementation of $5 \mathrm{~S}$ the scores varied from poorto-good (scoring from 1 - 3) related to the impact on productivity for quality of working place, quality and moral of staff and safety of work place. However, after the implementation of 5S, the scores had changed which varied from good-to-excellent (scoring from 3 - 5).

\section{CONCLUSION}

$5 S$ technique is an inevitable tool to enhance the productivity, safety, acceptable working environment, optimal inventory management and resultant financial benefits of saving inventory cost, smooth workflow, uninterrupted access to material and tools as when required. This technique has stood the test of the time for improving quality in various organisations such as healthcare, industrial areas, business sectors, educational institutions and so forth. Implementation of $5 \mathrm{~S}$ techniques in any sector can engender remarkable changes and proliferating benefits at workplace; however, toplevel management and employees' commitment towards the adherence for sustaining the $5 \mathrm{~S}$ principles is a must.

\section{REFERENCES}

[1] Esain A, Williams S, Massey L. Combining planned and emergent change in a healthcare lean transformation. Public Money and Management 2008;28(1):21-6.

[2] Suárez-Barraza MF, Ramis-Pujol J. An exploratory study of 5S: a multiple case study of multinational organizations in Mexico. Asian Journal on Quality 2012;13(1):77-99.

[3] Pandya VP, Patel UV, Kanabar BR, et al. Evaluation of implementation of "5S Campaign" in urban health center run by municipal corporation, Gujarat, India. Int J Community Med Public Health 2015;2(3):217-22.

[4] Kanamori S, Shibanuma A, Jimba M. Applicability of the $5 S$ management method for quality improvement in health-care facilities: a review. Tropical Medicine and Health 2016;44:21.

[5] Kanamori S, Sow S, Castro MC, et al. Implementation of 5S management method for lean healthcare at a health center in Senegal: a qualitative study of staff perception. Global Health Action 2015;8:10.3402/gha.v8.27256.

[6] Aziz ARA, Nishazini MB, Fareza, et al. Survey to see the impact of $5 \mathrm{~s}$ implementation among staff of Kpj Seremban specialist hospital, Malaysia. IOSR Journal of Business and Management 2014;16(3):82-96. 